\title{
Je vous Salue Marie: um filme cheio de graça
}

Annie Goldmann

Traduçáo: Mário Laranjeira

O perfume de escândalo que cercou o lançamento do filme de Godard obscureceu o seu verdadeiro significado. Considerado sacrilego por alguns, incompreensível por outros, a polêmica ocultou a profunda espiritualidade, evidente, entretanto, desta obra. Como sempre, Godard surpreende ao mesmo tempo pela novidade de sua abordagem, pela forma original e pela audácia da mensagem.

Diante do mistério da natividade de Jesus, Godard simplesmente perguntou a si mesmo: como contar essa hist6ria em nossa modernidade? Como contar um acontecimento tăo extraordinário que se deu a 2 mil anos e que $\epsilon$ o fundamento de fé de milhōes de indivíduos no mundo e, principalmente, como contálo em função dos modos modernos de comunicação?

Enquanto Pasolini, com O Evangelho segundo São Mateus, permanece no registro são-sulpiciano da reconstituição histórica e da mensagem tradicional cristã, Godard tenta dela fazer a narrativa como se estivesse se dirigindo a crianças da nossa época, habituadas com os heróis das séries televisionadas e com a leitura das histórias em quadrinhos. É por isso que transpōe o maravilhoso cristáo para o mundo imaginário de hoje, mistura de Pieds Nickelés e de Star Trek. Em vez de um anjo do outro mundo, Gabriel $€$ um homem comum, que viaja de avião; já não é só e seráfico, mas pragmático e acompanhado por uma garota maliciosa, como a heroína de Alice no Pats das Marcuilhas; a estrela dos Reis Magos é substituída pela bandeirinha de um carro-socorro; Maria E filha de um frentista e membro de um time de basquete, e Jose $€$ motorista de táxi... Gente simples, comum, exatamente como eram os pais de Jesus no tempo de Herodes. $O$ lugar já não é o campo primitivo, mas a cidade com as suas atividades - 0 trabalho de Jose, as relaçōes humanas, as relaçóes difíceis entre os homens e as mulheres, uma cidade alheia aos mistérios da fé, onde Maria vai encontrar-se sozinha para enfrentar o seu destino em meio à indiferença e ao ceticismo que caracterizam o mundo moderno. Esta opção de atualizar o acontecimento tem por função recolocar a problemática da mensagem cristã no mundo de hoje e não mais relegá-la ao museu imobilizado da instituição religiosa; os cartóes repetitivos e insistentes Naquele tempo servem para marcar, ao mesmo tempo, a intemporalidade e a contemporaneidade do acontecimento. Ao transportar rigorosamente a natividade para o mundo atual, Godard atualiza por isso mesmo a mensagem milenar e the confere perenidade.

Eis por que as duas personagens principais estāo bem situadas em sua época e vivem os conflitos de um casal moderno: José tem um caso com outra mulher e Maria duvida do seu amor.

Entretanto, de acordo com a tradição, Maria $€$ jovem, inocente e virgem. Diante da incapacidade da ciência para explicar a sua milagrosa fecundação, a moça vai aceitando pouco a pouco o inacreditável por caminhos outros que não os đa razão. Como imaginar, em nossa Época, semelhante acontecimento e como fazê-lo aceitar aos outros? A princípio há a expectativa: a jovem espéra algo de extraordinário: "Indagava-me se algum fato notável ia acontecer na minha vida" pois, contrariamente aos homens, "todas as mulheres desejam algu- 
ma coisa que seja única neste mundo". Em seguida, após a Anunciação, ela vai aos poucos assumindo o seu destino e descobrindo uma outra dimensão na vida, uma dimensão secreta que não pode partilhar com ninguém, porque cada um deve fazer a sua própria descoberta da espiritualidade. "Quero que a alma seja corpo e não se poderá dizer que o corpo é alma (...) Não mais haverá sexualidade em mim, conhecerei o discurso verdadeiro da alma." Mas Maria é feita de carne humana, tem desejos de mulher e a castidade que se impōe lhe pesa. Nua na cama, vê-se a braços com o desejo, como todas as mulheres; e trava um combate desgastante contra a tentação; daí as alusões à masturbação recusada, que são talvez chocantes, mas que se inscrevem perfeitamente no projeto godardiano de tornar viva e credível a personagem. Tais tentações não empanam a espiritualidade de Maria, ao contrário, é pelo combate contra si mesma que atinge o mistério do espírito e se eleva em relação aos outros. Se tudo lhe fosse dado, se tudo the fosse fácil, o seu mérito seria menor. A sua ascese não está definitivamente adquirida, é o resultado de um esforço sobre a carne, sobre a vida cotidiana. Godard transgrediu a imagem tradicionalmente passiva de Maria, simples receptáculo da Palavra, simples instrumento da Divindade, para the dar uma consciência, uma elevação pessoal que a coloca acima de todos os outros. Ela adquire, enquanto mulher, uma verdadeira grandeza; ela é cheia de graça.

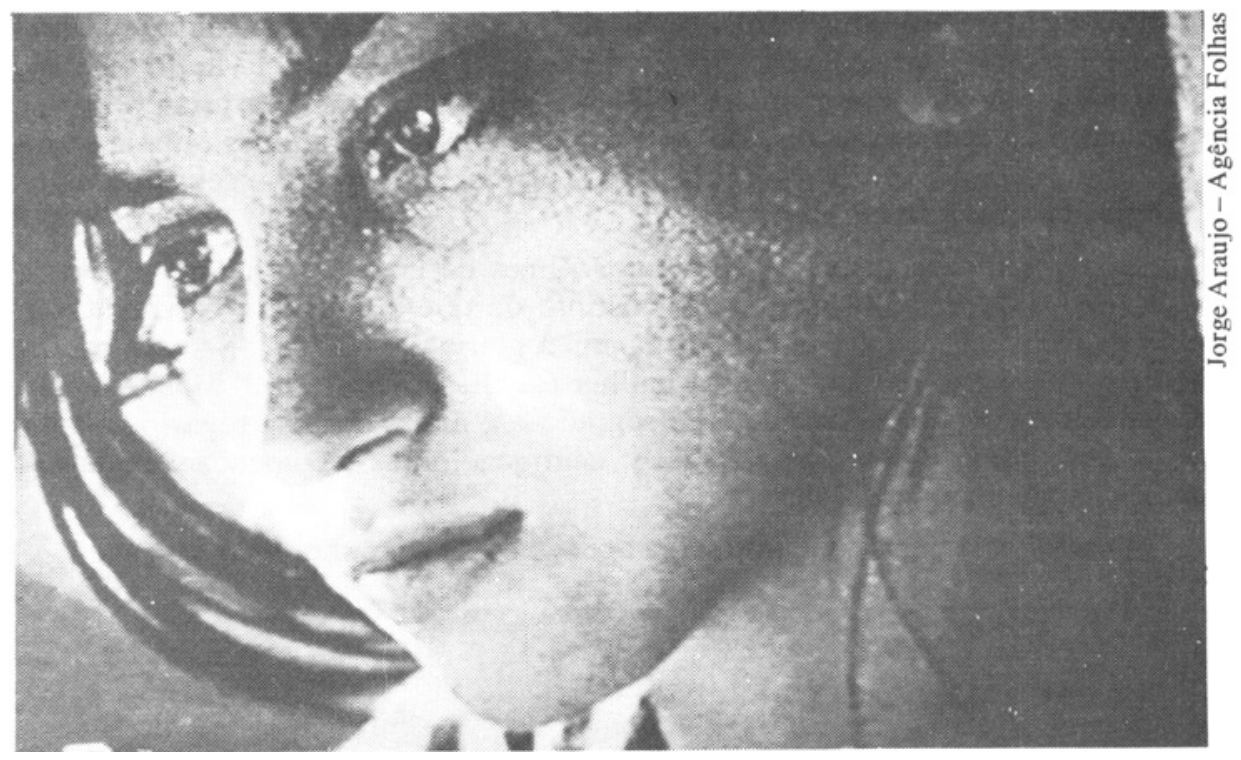

Para dar ao acontecimento uma significação ainda maior, Godard o liga ao cosmos. Maria está sozinha no meio dos seres humanos. "Há muito tempo não sei o que é uma conversação comum (...) Eu quisera falar como toda gente." mas o universo inteiro participa da gestação miraculosa, os elementos e os astros - a lua, principalmente, astro feminino por excelência - acompanham-na; pela janela entreaberta do quarto, durante as noites solitárias e as sestas abrasadoras, são os seus únicos confidentes, testemunhas protetoras do seu ventre que se arredonda; o vento, a água, os campos estão no ségtc lo que os homens ignoram. Maria está próxima do cosmos em movimento que, como Jesus, é criado por Deus. Mesmo o homem de ciência, o professor que tenta explicar aos seus alunos as leis da criação, acaba por admitir que um grande computador com uma inteligência fabulosa é o único ser que pode estar na origem da complexidade do universo. "A vida foi fruto de uma vontade, desejada, prevista, ordenada por uma inteligência resoluta." A intervenção divina se dá em todos os níveis: no da criação e no da revelação através do menino que vai nascer ${ }^{1}$. Há

${ }^{1}$ Trata-se, bem-entendido, de uma análise do filme e não das minhas posiçōes pessoais. 
um paralelo voluntário entre a fé de Maria e a ciência que é incapaz de explicar racionalmente a origem da vida. Numa síntese ousada, Godard remete o nascimento de Jesus à grande questão do Princípio.

Longe de ser o ancião passivo da tradição cristā, Jose € um homem jovem, ardente (tem uma amante), materialista, sem ideal, que recusa obstinadamente a renunciar aos seus direitos sobre Maria. Será necessária a intervenção truculenta de Gabriel, que mais parece um executor de quadrilha do que um enviado angélico, para obrigá-lo a isso. A sua incompreensāo não é senão um paradigma da incomunicabilidade do casal moderno e do egoísmo masculino. Durante algum tempo ele cultiva uma dupla relação amorosa, exatamente como o professor que rompe brutalmente com a sua jovem amante para manter o próprio conforto. O amor que José tem por Maria é a sombra da sombra, prisioneiro do ciúme, furioso por ser excluído, ele quer entender tudo, esquece a confiança, como os outros. Usa bculos de cego. Também ele terá de percorrer o seu caminho pessoal para descobrir em si o verdadeiro amor e aceitar Maria em sua diferença, para acreditar, também ele, que o esptrito age sobre o corpo e não o contrário.

A segunda parte do filme, mais rápida, esboça o destino do menino, mas sobretudo a evolução de Maria alguns anos após o acontecimento tão grande que tudo é consumido. O que nos mostra Godard é um casal banal, um marido autoritário e um garotinho voluntarioso, mimado pela mãe. Na realidade, Maria conhece o destino de seu filho; longe de se opor a ele, entrega-lhe o menino, como se esse destino não mais lhe dissesse respeito. $O$ gesto da criança explorando-the o corpo por debaixo do vestido não é obscenidade, mas o último vestígio da ligação extraordinária que existiu entre o seu corpo e o seu filho, ligação única de que José está excluído.

Como acontece com freqüência nos filmes de Godard, a mulher é dotada de um poder de adivinhação, de um instinto de que o homem é desprovido e, nesse sentido, este filme é uma homenagem à gloria da mulher. "Sempre me indaguei o que é que se sabe de uma mulher (...) há um mistério." Mas o mundo em que vivemos já não percebe esse segredo e é muito duro carregá-lo na soliđão. Maria, como todos nós, esqueceu; negligenciou as recomendações da pequena acompanhante de Gabriel:

"Maria, seja dura, seja pura, siga apenas o seu caminho. Não esqueça".

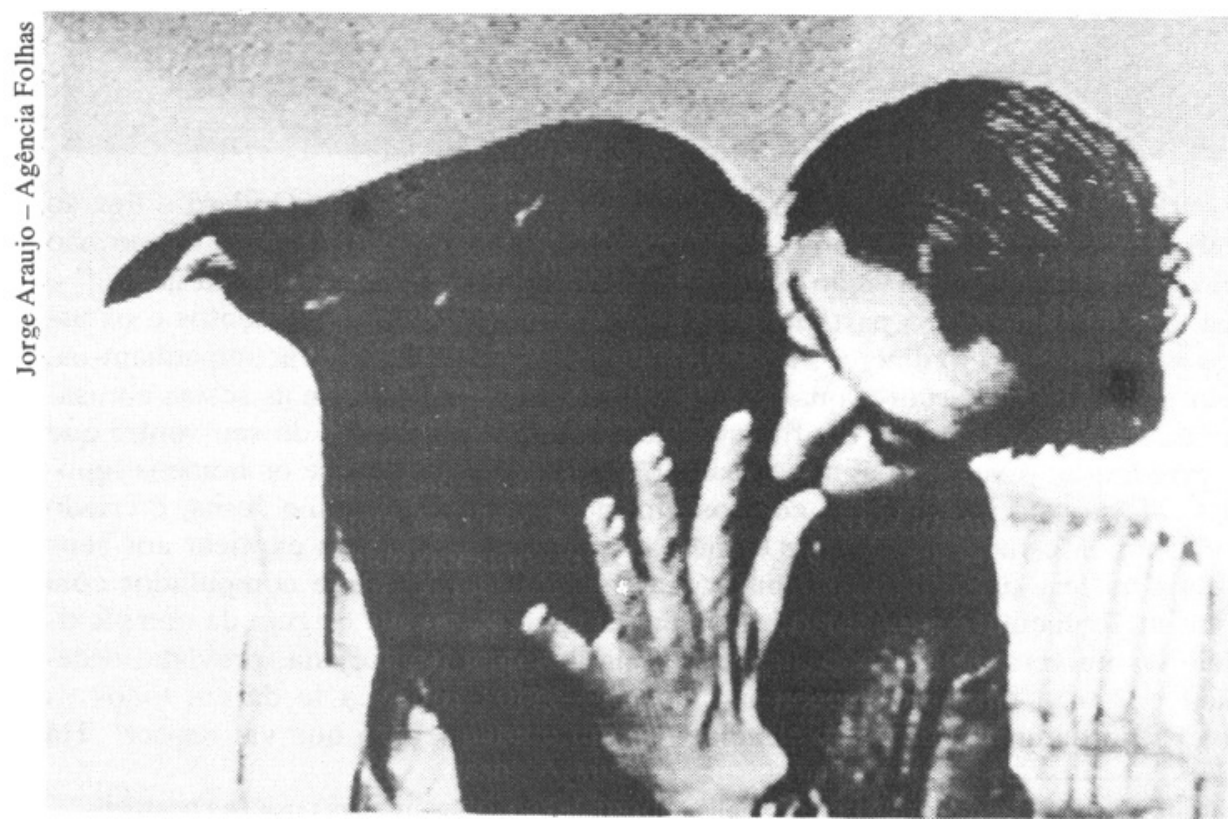


Ela voltou a ser uma mulher como as outras, que caminha pelas ruas da sua cidade, dirige o carro e se pinta. Perdeu a sua inocência e purreza. Eis por que, quando Gabriel cruza com ela por acaso e a interpela: "Áve, Maria", a lembrança da extraordinária missão de que fora investida e que abandonou the aflora à mente por um instante; um véu de nostalgia e de melancolia - de culpa talvez - enrijece-lhe o rosto maquilado. Uma hesitação e... o batom se esmaga sobre a boca aberta, buraco negro, obsceno, mudo sobre o que foi e não mais será. Não haverá Mater Dolorosa nem Rainha do Céu; resta uma mulher comum que se juntou à materialidade do mundo. "Eu, sou algo como virgem, e nunca quis ser nada disso."

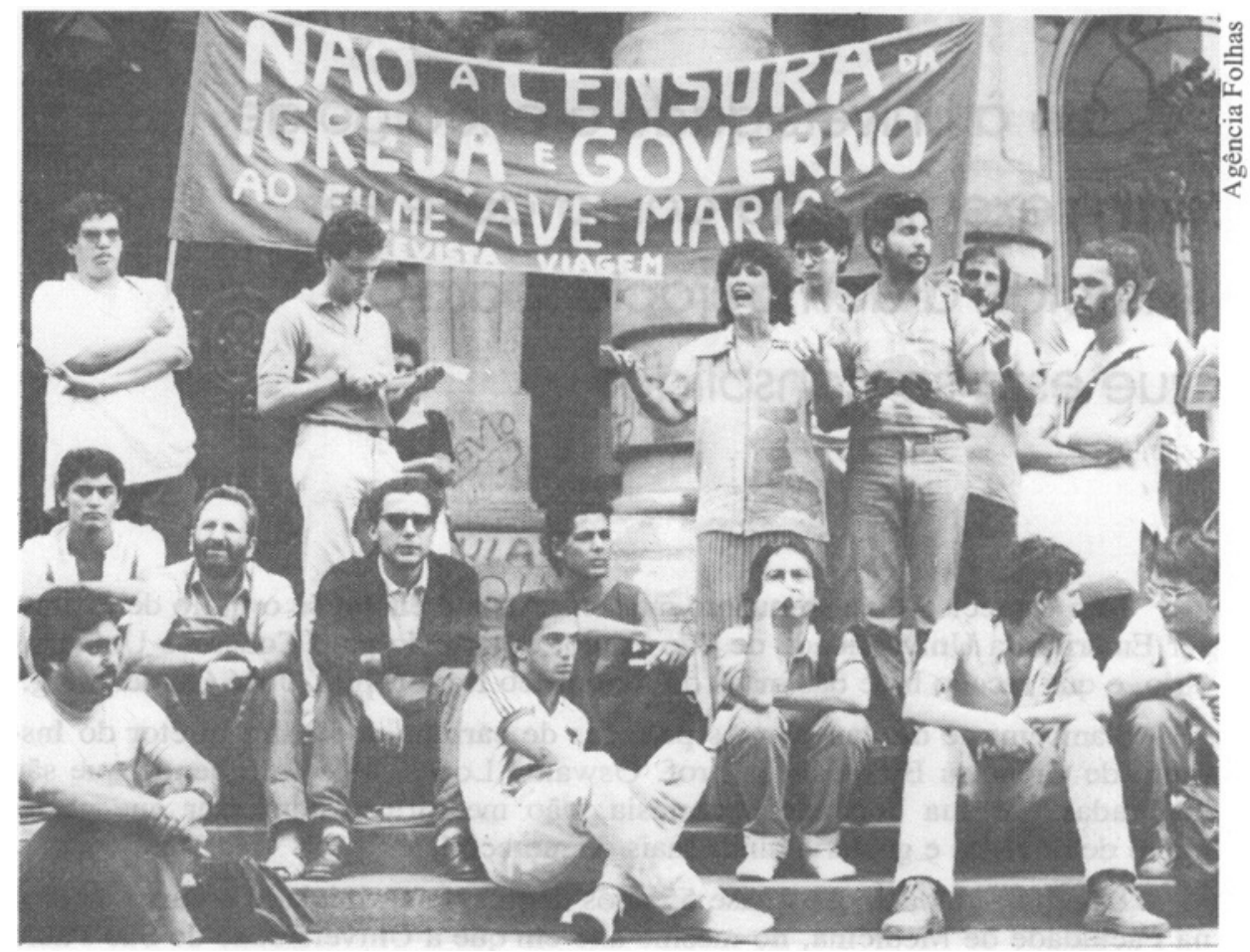

Para contar esta história moderna, Godard utiliza uma linguagem moderna, aquela que uma criança de nossos dias conhece. O filme está construído em tomadas fixas, como figuras de história em quadrinhos bem enquadradas, legíveis, entrecortadas de cenas paralelas que fazem alternar os dois universos, o de Maria, que sabe, e o dos outros. Aí tem cabimento o humor, as personagens estão muito próximas dos estereótipos das histórias em quadrinhos, como o anjo Gabriel, desajeitado e violento, moderado pela mocinha ("Não, não, tio Gabriel, você está se enganando de texto."). É o universo infantil que Godard tenta reencontrar, desembaraçado de toda hagiografia ${ }^{2}$. Mas a conclusão permanece amarga: a oportunidade dada à humanidade foi perdida e esquecemos que ela nos foi dada.

2 Em dois lugares, entretanto, ele parece fazer concessões à imaginária tradicional: quando do nascimento de Jesus, algumas tomadas de neve, de uma vaca e de um jumento inserem-se artificialmente, e quando o rapazola atribui aos seus companheiros de brincadeiras os nomes de seus futuros discípulos. Por outro lado, a frase "Eu sou aquele que é." pronunciada pelo menino parece uma interpretação abusiva, tendo sido dirigida por Deus a Moisés e certamente não por Jesus.

Annie Goldmann E diretora de pesquisas na École des Hautes Études en Sciences Sociales (França) e participante de dois Cafés Acadêmicos no IEA em 1988. 